\title{
A smart web of firms, farms and internet of things (IOT): enabling collaboration-based business models in the agri-food industry
}

\author{
Maral Mahdad and Mustafa Hasanov \\ Business, Management and Organization Group, Department of Social Sciences, \\ Wageningen University and Research, Wageningen, The Netherlands \\ Gohar Isakhanyan \\ Wageningen Economic Research, Wageningen University and Research, \\ Wageningen, The Netherlands, and \\ Wilfred Dolfsma \\ Business, Management and Organization Group, Department of Social Sciences, \\ Wageningen University and Research, Wageningen, The Netherlands
}

\begin{abstract}
Purpose - All firms' business models are based on their interdependencies with other parties in their ecosystems. The Internet of Things (IoT) is beginning to fundamentally disrupt the agri-food industry, forcing the ecosystem to change. When an ecosystem is transforming, the interdependencies among its actors can create friction. Technology providers and core actors should consider these interdependencies as they update their strategies for value creation and capture. The purpose of the present research is to consider what it might take for agri-food firms to capitalize on these interdependencies by moving from traditional business models to business models based on collaboration and open innovation.

Design/methodology/approach - The present paper draws on data from four online focus groups that we created to discuss how to co-create the business models agri-food firms need in a constantly changing environment. The paper presents an application of phenomenon-driven research (PDR), an engaged methodology. The study method enables novel pathways to develop and implement innovative solutions. This study draws on the interaction of theory and practice and involves multiple stakeholders with varying roles in the agri-food ecosystem.

Findings - The authors found that any open innovation setup in agri-food needs to constantly reconfigure itself to balance the needs of farmers and the needs of the market. This interplay can only support the IoTenabled ecosystem if continuous interaction and negotiation occur among various stakeholders of the food system. When the farmers' needs and the market's needs are aligned, the space for developing a collaborative and open business model is prepared.
\end{abstract}

(C) Maral Mahdad, Mustafa Hasanov, Gohar Isakhanyan and Wilfred Dolfsma. Published by Emerald Publishing Limited. This article is published under the Creative Commons Attribution (CC BY 4.0) licence. Anyone may reproduce, distribute, translate and create derivative works of this article (for both commercial and non-commercial purposes), subject to full attribution to the original publication and authors. The full terms of this licence may be seen at http://creativecommons.org/licences/by/4.0/ legalcode

The work presented in this paper was supported by the EU H2020 project Internet of Food and Farm (IOF2020). The authors would like to thank IOF2020 and its participants who were most generous with their time and availability.

Funding: The study is funded by the European Commission, Horizon 2020 Framework Program for research and innovation under grant agreement number 731884, and the Internet of Food and Farm 2020 (IOF2020).

A smart web of firms, farms and IoT

Received 9 July 2021 Revised 17 November 2021 7 January 2022 Accepted 12 January 2022 
$\mathrm{BFJ}$

124,6

Originality/value - The insights gained from this study inspire action and commitment to common goals when developing collaboration-based business models (CBMs). The paper offers insights for players in the agrifood industry who are considering CBMs in the course of digital transformation.

Keywords Open innovation, Ecosystem, Collaboration-based business model, Internet of things,

Agri-food system

Paper type Research paper

\section{Introduction}

Open innovation (OI) in the food industry is trending as a way to increase competitiveness and sustainability (Annosi et al., 2020; Kafetzopoulos et al., 2020). Due to the increased dynamicity and interdependencies among players in food systems, the traditional supply chain view is transforming, and players are taking into account a much broader network of stakeholders (Liu and Stephens, 2019). OI is a new paradigm in the agri-food sector. Research on OI shows that different industries indicate particularities in their approach toward inter-firm collaborative innovation and how they manage it (Schoen, 2017). The agri-food is no exception. The OI term is used in its alternative forms in the agri-food sector such as co-innovation (Bossink, 2002; Bitzer and Bijman, 2015); and collaborative innovation (Makimattila et al., 2013). However, OI paradigm offers a more robust framework for orchestrating inter-firm collaboration in this sector. The recent events related to COVID-19 are placing additional pressure on companies to look for more collaborative approaches toward innovation and business models (FAO, 2020), heightening calls to adopt a common framework for collaborative innovation in the agri-food sector, namely OI. As they cope with the disruptive, complex, non-linear phenomena associated with digitalization, firms face a catch-22 dilemma: Firm A cannot finalize its business model until Firm B has finalized its business model and Firm B cannot do so until Firm A has done so. The present research dives deep into what it takes for agri-food firms to avoid that paradox by developing collaboration-based business models (CBMs) for IoT-enabled ecosystems.

The Internet of Things (IoT) has drawn attention in recent years for its potential to transform agriculture and food systems. IoT is a smart network of sensors, actuators, robots, drones and other connected devices that allow for an unprecedented level of automation and control. Using IoT could, among other things, improve food quality; control the use of pesticides, herbicides and artificial nutrients; monitor environmental circumstances; and provide real-time data supporting stock management (Accorsi et al., 2017; Jagtap et al., 2019; Ying and Fengquan, 2013). A recent report suggests that IoT offers unique opportunities to achieve targets set by Sustainable Development Goals (SDGs) and the European Green Deal (Renda and Laurer, 2020). As progressive as IoT seems, however, the adoption of IoT tools and services is happening in a somewhat uncoordinated way, and businesses engaged with it face challenging decisions whose outcomes will affect their own future directions and those of the agri-food sector. Accorsi et al. (2017) have stated that a better understanding of the application of IoT in the food supply chain in a real-world environment could potentially validate its benefits for agri-food system stakeholders. According to Del Giudice (2016), the emerging management research field on the application of IoT should investigate how IoT transforms internal and external business processes. Other researchers call for a deeper understanding of the interplay among the building blocks of business models in response to the transformations IoT requires from organizations' value creation and capture strategies (Metallo et al., 2018). Caputo et al. (2021) suggest that future research in digitalization and its impact on firms' strategies should go beyond financial outcomes and consider non-financial impacts in their assessment, such as shared value creation with and for stakeholders operating in firms' business environment.

As agri-food technology providers increasingly collaborate through the IoT, the optimization of their business models (BMs) is imperative for their success. In today's 
dynamic competitive landscape, characterized by technological advancements, high-velocity markets and fast-changing customer and stakeholder requirements, those BMs are subject to continuous adaption and innovation (Wirtz et al., 2016). In recent years, scholars have increasingly focused on the nexus of BMs and digitalization (Caputo et al., 2021). Both scholars and practitioners have denounced the adoption of overly static BMs (Chesbrough, 2007; Cosenz and Noto, 2018; Demil and Lecocq, 2010; van Putten and Schief, 2013; Schaffer et al., 2019). BM research has been shifting from a static conceptualization of business models toward a more dynamic and iterative one (Kranz et al., 2016; Saebi and Foss, 2015; Schneider and Spieth, 2013; Burkhart et al., 2011). The use of IoT in agri-food supply chains substantially increases the interdependencies among the partner and each firm's BM needs to reflect that. The interdependencies among agri-food actors call for bringing in the innovation ecosystems perspective to replace the static supply chains perspective. Innovation ecosystems actors "start with a value proposition and seek to identify the set of actors that need to interact in order for the proposition to come about" (Adner, 2017, p. 41). This perspective allows a collaborative exploration process (Dattée et al., 2018), which is especially appropriate for coping with the current changes as digital transformation hits agri-food. The innovation ecosystem perspective encourages shared value creation and capture strategies (Caputo et al., 2021). The development process of CBMs for ecosystems should result in business models that accommodate each actor's requirements for value creation and capture (Oskam et al., 2021). The present research discusses the collaborations that need to be understood and integrated with the business models of IoT-enabled firms within agri-food ecosystems in line with open innovation paradigms. It sheds light on the exploratory process that leads to new BM development that accommodates the collaborative aspects of agri-food systems. However, to date, our understanding of how agri-food ecosystem actors could integrate different stakeholders' perspectives in their shared value proposition strategies is limited.

Therefore, this article explores the antecedents of developing CBM of organizations working in IoT and agri-food. Furthermore, it describes how those firms employ different strategies in different contexts. Our data comes from four online focus groups that were created to discuss what it will mean to co-create the business models needed to enable agrifood firms to continually update their strategic choices in a changing environment (Trimi, and Berbegal-Mirabent, 2012) and allow practitioners to make better BM decisions. Hence, this article is guided by the following questions: What informs the decisions of agri-food firms using IoT to engage in CBM? And how can they develop a shared value proposition strategy?

\section{Background}

\subsection{Digitalization and business models}

For decades, research on the application of IoT in various contexts highlighted the importance of organizational transformation for firms in the digital age. It argued that they should adopt new industrial practices and use smart technologies. Schuh et al. (2017) claim that digital transformation goes beyond integrating digital technologies and information and communications technology (ICT) into manufacturing processes; it includes aligning with partners to access external knowledge. Along with stressing the role of unified knowledge management within and outside firms' boundaries through ICT integration, researchers stress organizational transformation to enable the focal firm to be agile and responsive to a fast-paced, changing environment (Bresciani et al., 2018). Digitalization promises selfregulating and inter-connected systemic value creation mechanisms for industries (Liao et al., 2017). The agri-food sector has been proactive in implementing digital technologies for decades, resulting in a greater need for networked and open approaches (Bresciani, 2017). Advancements in precision agriculture, farm management information systems, remote
A smart web of firms, farms and Io $\mathrm{T}$

1859 
$\mathrm{BFJ}$

124,6

1860 sensors and robotics have alleviated obstacles for transforming agri-food companies (Mondino and Gonzalez-Andujar, 2019), but have also complicated their traditional approach to creating and capturing value. Technologies such as the internet of things (IoT), big data, artificial intelligence and blockchain are enabling the agri-food industry to evolve into a socalled system of systems that is agile, smart and decentralized (Lezoche et al., 2020), yet brings its own imposing challenges.

Such a complex, dynamic system requires organizations to adapt their strategies. Researchers assert that digital transformation requires firms to transform their business models (Müller et al., 2018; Wei et al., 2017). However, to what extent the business model transformation is conducive to the system of a systems approach has yet to be explored. Müller et al. (2018) claimed that the extensive connectivity could allow organizations to create and capture new data-driven value. However, these things are only possible when value cocreation is enabled in ecosystems where actors interact and seize opportunities together. Hence, firms' individual creation of value from their resources or their business environment (Porter, 1985) is transforming into ecosystem-wide value creation (Adner and Kapoor, 2010). Collaboration is needed to create value (Zott and Amit, 2010). This point is underscored by recent research on the necessity of leveraging OI and adopting open business models in manufacturing firms that are experiencing digital transformation (Obradovic et al., 2021). Like the open innovation paradigm, business ecosystem theory suggests companies can gain a competitive advantage by redesigning the ways they create and capture value through system-level approaches (Wei et al., 2014). Firms need to generate and adopt new business models focused primarily on partnership with ecosystem actors (Chesbrough and Bogers, 2014). CBMs are required to cope with digital enabled ecosystem (Caridà et al., 2015).

\subsection{Collaboration-based business model}

Extant research supports integrating ecosystem actors into the business model processes (Amit and Zott, 2012; Giesen et al., 2010). However, in practice, opening up the business model to accommodate the expectations of other stakeholders brings complexities and challenges; fundamentally, firms tend to have divergent objectives (Laudien and Daxböck, 2016). As a solution, researchers call for CBMs, which can lead to a better understanding of shared value, a reduction in opportunistic behaviors and an increase in knowledge sharing (Cantele and Cassia, 2020). However, the literature on open and CBMs only discusses how a focal organization embraces external stakeholder competencies; it does not address open business models as a tool to facilitate open innovation in ecosystems by involving all stakeholders (Ghezzi et al., 2021). Insufficient attention has been paid to the antecedents of CBMs and how the antecedents can be operationalized (de Man and Luvison, 2019).

de Man and Luvison (2019) introduced three models for the operationalization of CBM: sharing, specialization and allocation. In the sharing model, firms pool their similar capabilities to achieve to achieve greater scale or network effects. The benefits of this approach include horizontal integration in the value chain (Dussauge et al., 2000). In the specialization model, firms combine their complementary capabilities to offer products or services each could not develop alone (Grant and Baden-Fuller, 2004). Finally, in the allocation model, firms have overlapping capabilities, and one of them is more proficient at a specific task useful to the alliance. The firms create combined value by allocating each activity to the partner best suited to do it (de Man and Luvison, 2019).

This seminal research on CBM suggests that companies often choose a primary and static business model. However, when complexity arises, either in the market or among stakeholders during collaboration, constantly reconfiguring the model and realigning the partners' interests becomes unavoidable. 
Adner (2017) claims that understanding the evolving nature of ecosystems process perspectives appear beneficial to how actors with divergent objectives resolve tensions and how this leads to sustainable business models. A sustainable business model is a CBM, as defined by Geissdoerfer et al. (2016): "a simplified representation of the elements, the interrelation between these elements, and the interactions with its stakeholders that an organizational unit uses to create, deliver, capture, and exchange sustainable value for, and in collaboration with, a broad range of stakeholders" (p. 1219). This emphasis on the collaboration aspect of value creation and capture strategies in ecosystems that requires further scholarly attention. Tensions among ecosystem members, if they are not resolved, may lead to dysfunctionality in ecosystems at the levels of both value creation and value capture. Jacobides et al. (2006) showed that a source of tension is the ever-changing strategies each actor uses to create and capture value. The tension increases as the value creation occurs at the level of the ecosystem while the value capture occurs at the level of each actor (Lepak et al., 2007; Ritala et al., 2013).

In a few studies, the business model is seen as a collective tool (Oskam et al., 2021) that enables actors to iteratively explore various forms of economic and non-economic value within an ecosystem. At the beginning of their research, Oskam et al. (2021) assumed the CBM development process would result in a sustainable business model that created and captured all value types at the ecosystem level. Instead, they found that ecosystem actors were engaging in the process of what they called "valuing value" - co-exploring environmental, social and economic value creation and capture - while accommodating one another's interests. Although the study shows that a clear, shared vision and a time horizon help develop a viable CBM, it does not indicate how, in practice, the actors can reach that clear, shared vision and time horizon. These scholars call for more research to understand what kind of orchestration should be applied in settings where a focal actor coordinates the process, or in which no focal actor takes responsibility for the coordination of an ecosystem. Recently, researchers found a shift in firms' business logic to realign their purposes with those of their stakeholders: they needed to systematically create and capture economic, environmental and social value as a collective action, because otherwise, they would lose competitive advantage (Joyce and Paquin, 2016). Breuer et al. (2018) have argued that developing sustainable business models requires active facilitation to allow the coexistence of divergent interests and goals among stakeholders. Therefore, collaborative settings for developing business models are necessary to avoid the emergence of conflict. These researchers also claimed that in addition to involving the perspective of each stakeholder, it is also necessary to reformulate business model components and create a shared understanding of sustainable business models. However, the empirical evidence on the dynamics between business model components and their realization by stakeholders in a network-centric business model is scarce (Breuer et al., 2018). Therefore, the present research seeks to understand better the dynamics among actors in an IoT-enabled ecosystem working to implement CBMs.

\section{Methods and data analysis}

\subsection{Research context}

This article engages with, builds on and extends earlier research exploring the potential of IoT technologies for the European food and farming industry (van Hilten et al., 2020). In traditional management and organization sciences, it can be challenging to observe the specific details of ongoing collaborations between stakeholders, as typical research designs that engage with participants are somewhat detached from what is happening under the surface of these collaborations. Equally, detachment from the environment in which those participants operate makes it harder to observe their challenges and their successes. To
A smart web of firms, farms and IoT

1861 
$\mathrm{BFJ}$ 124,6

\section{2}

overcome these obstacles, we set up four interactive online focus groups with participants from four use cases. These four use cases were a part of [name of project hidden for review purposes], which explores the potential of IoT technology in farm environments through several use-cases. Specific IoT-enabled firms constitute these use-cases and have supported developing, testing and demonstrating Io $T$ technologies for the agriculture and food industry on a European Union (EU) level. We often referred to the focus groups as workshops, so participants felt more empowered and engaged in our research than they would have been as simple objects of study. Information gathered was anonymized to reduce the possibility of linking it retroactively to interviewees or specific firms.

\subsection{Research method}

This article represents the application of phenomenon-driven research (PDR) (Schwarz and Stensaker, 2016). PDR is an engaged methodology. It has been shown to inspire action and enable novel pathways to develop and implement innovative solutions (Von Krogh et al., 2012). PDR welcomes interaction between theory and practice and typically involves multiple stakeholders with varying roles in an action learning framework. Therefore, this research approach was suitable, as the purpose of this study is to build a common framework for describing, and possibly helping, stakeholders within the [name of research project hidden for review purposes] to co-create CBM by engaging and enriching prior knowledge, resources, and capabilities.

The members of the focus groups belonged to organizations involved in implementing IoT solutions for the agri-food sector. The individuals were mainly selected for their ability to converse among themselves and reflect on their own experiences (Leung and Savithiri, 2009). We grouped the use cases based on prior knowledge and engagement in activities within the overarching research project. The group discussions were semi-structured to ensure that the discussion remained relevant while allowing the researchers and participants to deviate from the plan when needed (Blee and Taylor, 2002). Each workshop was problem-oriented and focused on a specific problem, its conceptualization and its potential solution. The aim was to facilitate knowledge exchange and engage participants in working together to support new collaborations. A list of participants and their affiliation with institutional stakeholders is provided in Table 1.

The structure of the workshops is described in Figure 1. Each workshop's activities were based on prior outcomes from the overarching research project and some of the bottlenecks

\begin{tabular}{ll}
\hline Tomaz & Nonprofit business support organization \\
Nikos & SME, information technology and services \\
Harris & SME, IoT original equipment and solution provider \\
Constandinos & Research institute/university \\
George & Research institute/governmental agency \\
Albert & $\begin{array}{l}\text { Research and development of crop protection products, seeds, agricultural chemicals, and } \\
\text { biotechnology products }\end{array}$ \\
Jason & Agricultural machinery company \\
Andres & Agricultural machinery, precision farming and agriculture robotics provider \\
Daria & Farm equipment supplier \\
Klaus & Agricultural machinery company/manufacturer of agricultural software \\
Corne & Research institute/university \\
Tamme & Research institute/university \\
Stefania & Farm equipment supplier \\
Peter & Farmers' association \\
Jan Rijk & Mobile telecommunication company
\end{tabular}

Table 1.

List of focus group participants and their organization 
Understanding

support context

for CBM for loT
Discussing

interventions to

support CBM
Learning cycle,

CBM design

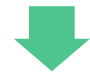

Problem co-
identification identification

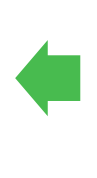

implication
Solution co-

identification

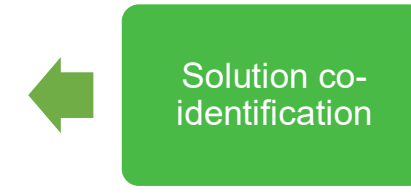

A smart web of firms, farms and IoT

1863

Figure 1.

Flow chart of the set of activities and structure of the workshops

they were experiencing. The workshops demonstrated our groups' conceptual frameworks, since we were asking them to come up with a design for a CBM that they would like to create.

The online focus groups were part of a long-term development cycle whereby participants grew as a learning group over the series of workshops. To build momentum, for each group, we developed different sets of questions designed to evoke increasingly profound responses based on participants' experiences and expertise in establishing collaborations. The first set of questions explored the main elements of a business model. Namely, we asked participants to ideate and reframe. During the ideation period, participants brainstormed ideas for a new business model. During the reframing period, they focused on conceptualizing alternative business models. The second set of questions provoked a deeper discussion of collaboration strategies that may not otherwise have presented themselves. We asked participants to envision, explore and assess the potential outcomes of the business model. The second question set also required participants to propose action formulation and define concrete actions for implementing the business model.

Each focus group included briefing documents and a set of activities, as well as a learning session structure (Figure 1). Owing to the circumstances around Covid-19, focus groups were conducted online over Microsoft Teams and Mural, enabling group meetings and digital collaborative space. The software also allowed meetings to be recorded by the research team. Thus each session was recorded, ensuring that the research team participated in the group discussions. The recordings captured not only the spoken words but also some unspoken reactions, which were used to explore participants' responses. Furthermore, the online environment allowed participants to share images, documents and additional information, which was crucial for keeping the discussions alive.

\subsection{Data analysis}

Each focus group recording was transcribed and the transcription was put into Atlas.ti, a proprietary software program used to analyze qualitative data, and coded accordingly. Data analysis was further enriched with the artifacts produced from the online sessions and the notes of the research team, including reflective notes on the sessions and audio-visual cues. The initial coding was based on the conversations and observations during the workshops. At this stage, we zoomed in on the conversations and noted down emerging ideas, relationships and key concepts used by the participants. The use of online tools assisted us, as participants could also share and write in the canvas provided (Figure 2). The second step in our coding was to combine and shuffle the themes and categories that emerged until 
BFJ
124,6

1864

Figure 2.

An example of the online sharing canvas used to identify the main themes of the analysis. Different colors indicate different participants

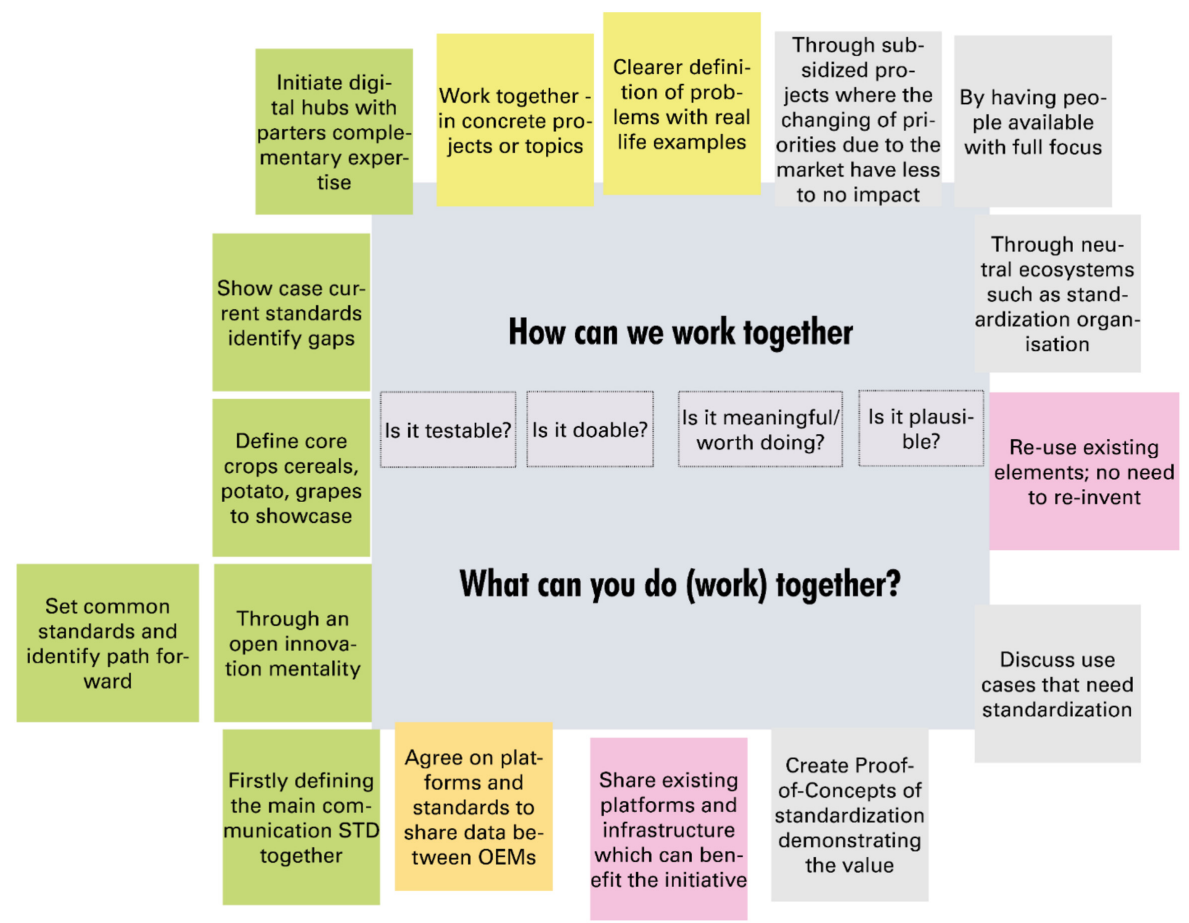

saturation was reached. We also identified some inductive codes that were not extracted from the literature and emerged from the group discussions during this stage. Finally, each code was juxtaposed with observations from the authors to ensure the validity of the findings. The two-stage coding allowed us to draw comparisons among the participants' statements and identify some key differences between the different interests the participants might have and their understanding of $\mathrm{CBM}$.

\section{Results}

The workshops identified the following two themes - Interplay and Alignment - to explore (a) the interplay of different priorities that arises while developing CBMs and (b) how those priorities could be aligned with one another.

\subsection{Interplay: how to define market needs for IoT in agri-food}

Participants at the workshops pointed out interplay between the various needs and expectations of the stakeholders developing IoT solutions for agri-food. The layers of interplay for the participants included in this research could be found in how they respond to the needs of farmers who are their customers, how they adjust to the market's needs, and how they interact with, integrate, and engage with changing demands to transform their business models.

4.1.1 Needs of the farmer: "Digital technology is not able to replace personal skill set.". One of the major priorities for the organizations involved in implementing IoT solutions was the socalled needs of the farmer. The discussions about the farmers' needs suggested that 
collaborative BM developers in this field have already been busy understanding the different needs and developing specific, tailor-made solutions. As Albert said,

If you talk about your needs, you have to specify what type of farming it is. When you are farming grains and you have a big acreage and you focus on grains, your needs are different than if you're growing potatoes.

Three things became clear at this point in the workshops: that there is no one-size-fits-all approach to developing BMs for IoT in agri-food, that businesses engaged in providing Io $\mathrm{T}$ have been driven by technological advancements rather than providing tailor-made solutions to farmers and that farmers have been reluctant to deploy IoT-based technologies. Central to these discussions was the fact that farmers have been reluctant to deploy IoT-based technologies. Tamme commented,

I have worked a lot with farmers, and I try to understand how tools and data can improve the daily work. I fully agree that our perception of what is needed is sometimes a little bit clouded by the opportunities that technology offers.

This point was echoed by the majority of the participants, who stated that when developing a $\mathrm{CBM}$, adjusting to the customers' needs, in this case, farmers, is as important as synchronizing and standardizing data.

A related point was how the farmers responded to the technology that providers offered them. During the workshops, the participants were asked to elaborate whether they know how their customers used the tools they had provided. Some respondents shared that generally, farmers were skeptical about using new digital technology and overwhelmed by the information (or sometimes by the lack of information) that the providers offered. Peter commented:

A farmer wants to be able to use the technology you give him. A contractor comes in with a new machine but he wants to continue working on the old machine.

This point suggests that there is a gap between the supply of the providers and the demands of their customers that requires further attention. The discussions around this topic also revealed that farmers do not need to use IoT solutions all the time, but mostly in peak performance times, such as harvesting or crop cultivation, when the they need to act swiftly to react to changing environmental conditions. Peter, who is experienced in working with farmers and farmers organizations, comments:

They need digital tools most when they are having peak moments. Whatever technology you offer, it should flow easily into their daily routines and practices.

It is not surprising, then, that while discussing the adoption rate of tools and data in agri-food practices, the workshops also touched upon issues of support and resistance from farmers. The following quote from Albert illustrates this point:

We had a star farmer. There was no need to convince him. But another farmer is more conservative and more opinionated. We had to convince him to use these tools. This year, apparently, there has been a change. He has started to use them and benefit from using them.

Hence, a central concern shared in the workshops was that no matter what BM IoT providers in agri-food are willing to pursue, they should focus on building trust and connecting with the more skeptical users.

4.1.2 Needs of the market: "Where there is a market, collaboration works fine". Another critical discussion point for the stakeholders involved in the workshops was to adjust their expectations about CBM to the needs of the market. There was a general agreement that the use of IoT in the agri-food industry is widespread and expected to grow. However, it was
A smart web of firms, farms and IoT

1865 
$\mathrm{BFJ}$

124,6

1866

difficult for the participants to speculate on what the needs of the market are, or even what their market is in a collaborative setting. As Peter said,

It's always hard to get a proper market, to get enough market where enough farms take advantage of the additional value that you bring.

Furthermore, when we asked the respondents to think about the needs of the market from the perspective of a collaborative working environment, there was a consensus that the different stakeholders would have different understandings of what is necessary for the market. One of the assumptions was that collaborations in the agri-food IoT domain would include differently sized companies with different expertise, resources and capabilities that operate in a shared ecosystem. The following quote from Jason confirms this:

A big company represents a big part of the market, and if you have small companies, they actually do the new things or interesting things.

While Jason's claim implies that there is a certain overlap between the different markets, in this case, by small and big companies in the agri-food industry, this also implies a risk of what is perceived as a market need or trend.

A similar view was shared by a representative of one of the major agrotechnology providers worldwide. Discussing experience in scouting for company expansion in new markets and industries and agri-tech innovations, Stephania noted that often, stakeholders may decide to collaborate and then "decide which market [they] want to go for and how to collaborate with the players in that market." While this statement implies that the needs of the stakeholders might precede the needs of the market, it raises the question of whether there is actually a need to develop new markets or whether it might be better to simply work on hidden synergies aimed at discovering market demand and user freedom. Commenting on experiences on developing a joint implementation strategy for smart solutions in Greece and Cyprus, Harris mentioned,

We are still pursuing this collaboration. We're still focusing on markets that we had already focused on before. The different aspect here is that we give the end-user the freedom to choose a more complete service.

The emphasis on service suggested that the customers' needs are transitioning from purely technology-based issues toward servitization and the identification of different demands in the use of IoT applications for agri-food production. The added value of rethinking the needs of the market, as Stephania argues, is about taking a "step back and starting to realize that the question that we should have is how to show, concretely, in the first place, to the farmers, that the technology has benefits." Hence, the quest to understand the needs of the market also associated to addressing the needs of the farmers and integrating them into the ecosystem.

\subsection{Alignment: how to bring the needs of farmers and markets together}

A vital element in the discussion on what should be at the core of CBM for IoT in agri-food was how to bring the needs of the farmers and market demands under a common umbrella. Here, the opinions of the workshop participants varied. About half of the participants believed that integration and interaction should be covered in the beginning stage of developing a CBM. The other half were more concerned with the marketing and pricing of the outcomes of CBM. Regardless of their differences, however, everyone agreed that aligning diverse needs and activities was essential. Those differences could be explained by the level of familiarity among the members of each of the two stakeholder groups and the business conditions under which each was operating. The first group had a long history of collaboration in various practice-oriented projects and industry-research collaborations. The 
second group was, at the time of workshops, intending to launch a common service and expansion using each other's infrastructures to access new markets. Two other reasons for the disagreement about which stage the alignment of business activities should occur in were that the agri-food supply chain is complex and that the different stakeholders move at different speeds. This point was articulated by participants who pointed out that most of the business models around IoT in agri-food involve different stages of product development and input from organizations with diverging and sometimes competing interests. Some participants noted that the alignment of any interests often takes a long time. As Tamme said,

It takes about ten years to bring to market what we developed from a scientific point of view, and in the meantime, farmers also have needs. It's very difficult to bring all this together.

Regardless of the significant mismatches between farmers needs and innovation, the importance of practice-oriented research and industry-research collaborations was often mentioned as a way to have a clearer definition of the priorities in bringing the needs of the farmers and the needs of the markets together. Peter expanded on the idea that some sort of intermediary organization might be needed to help with this task:

We have a lot of farmers who are not able to make huge investments but they would take the lead in an innovative direction because individually they can do it. They should do it together and they should rely on other organizations in the network to get the right thing going.

Some participants expanded on this idea and suggested that in the IoT of food and farming, collaborations should aim to balance heterogeneous partners without forgetting the perspective of the customer. On the whole, the participants asserted that integrated journey maps would add value for all cooperating agri-food IoT users, improving the performance of both the suppliers who offer products or services and the farmers who make use of them.

Another issue complicating business alignment that the participants mentioned was the difficulty of monetizing and measuring the success of collaborative ventures. Shifting alliances among organizations that differ in size and commitment to a shared outcome lead to uneasy relationships, difficulty in delivering products and inter-organizational tensions. Nikos put into words several questions that were on the minds of many participants:

How do we exchange data? How much do we exchange? How we quantify the data and put a price on it? And how do we share the extra value it generates?

Surprisingly, technical aspects of collaboration were commonly mentioned while discussing alignment strategies. The technical aspects, however, were often discussed in the early stage of product or service development. Along with some discussions on what types of data could be shared and how it could be shared and with whom, the fact that the technical aspects should be discussed in the early stage of product or service development also raised an interesting question: Whether CBMs would result in what one of the participant referred to as an "innovation chain"?. Similarly, Nikos mentioned:

If we're talking about a new product that we will have together, then yes, we need a more elaborate common business model. If not, we stick to existing solutions, taking advantage of the benefits of our collaboration, and we just enhance our own business model.

A recurrent sensitive issue in the context of alignment was organizational commitment in pursuing CBM. There was a consensus that IoT collaborations in agri-food could provide inspirations that offer solutions beyond this specific sector. However, it seemed that committing to CBM was not always prioritized, but relied on actions by specific individuals within organizations. As Peter said,
A smart web of firms, farms and IoT 
$\mathrm{BFJ}$

124,6
We have individuals working very hard to get further, and an organization that's more or less connected to them. But others do not agree. If we can fix those disagreements, that would help a lot.

While our workshops did not go into broader organizational aspects of commitments, the results suggested that CBMs were often seen as procedural goals that could result in a set of desired outcomes, with a handful of employees being committed to developing them. Regardless of these differences, alignment indicates shared envisioning and pointed to some specific elements that participants recognized as useful for developing CBM in the future.

\section{Discussion and conclusions}

\subsection{Discussion}

In exploring the underlying rationale of agri-food firms offering IoT solutions to develop $\mathrm{CBM}$, this research presents several interesting findings. First, the results suggest that in developing CBMs to enhance open innovation activities for an IoT-enabled ecosystem, stakeholders tend to focus on materials, technological preparedness and transferability. Given the nature of the solutions these firms offer, these results were anticipated. However, actors do require a more coherent approach to developing a shared proposition strategy. Second, our findings point out that personal motivation, professional preferences, social pressure and decision-making mechanisms within the macro environment of the firms are necessary to develop CBMs. Third, the company representatives included in this research agree that IoT applications in agri-food should be scalable and tailor-made at the same timeespecially as efforts to develop CBMs at this stage are aim to enable change and gain the support of farmers rather than forcing top-down solutions. It's important to focus on farmers who are less entrepreneurial and more resistant to change instead of only the front runners. Hence, the findings of this research highlight the importance of firms' adaptability skills for operating in dynamic market situations and motivating farmers to create opportunities for market change which is similar to findings of Alassaf et al. (2020) highlighting the importance of culture and attitude in embracing open innovation benefits during transformation.

Our results further support the idea of developing CBM that starts with the creation of a shared agenda among stakeholders who might otherwise have competing interests. As mentioned in the literature review, advancement in agri-food digital ecosystems has given rise to new requirements and varied weights to different stakeholders (Wirtz et al., 2016). On the nexus of digitalization and business models, our research underscores the importance of realizing tangible and visible advantages at the early phase of technology adoption to encourage user freedom rather than focusing on digital lock-ins in value proposition strategies. These results echo the complications of activating networked and open approaches to developing CBMs (Bresciani, 2017; Lezoche et al., 2020). There is an opportunity to co-create new markets simultaneous to discovering the market demand by all stakeholders, which results in reducing the risks for firms taking the lead in digital transformation. Consistent with the literature on open innovation and open business models (Chesbrough and Bogers, 2014), this research found that developing CBM enables opportunities for risk-sharing and new market entry success. Furthermore, CBM also create opportunities for organic development of ecosystems and value creation.

On the nexus of CBM development and digitalization, our research sheds light on the dynamics of interaction among actors. It contributes to the emerging literature of sustainable business models by re-emphasizing the interaction aspects of the definition of sustainable business model proposed by Geissdoerfer et al. (2016). Unpacking the mechanisms of the alignment of agri-food stakeholders, our research reveals the path toward more efficient deployment of technological solutions in the industry (Rashid et al., 2013). As our findings suggest, the focus on CBM for IoT-enabled firms in the context of agri-food should shift from being efficient to becoming meaningful. The willingness participate in developing CBMs by 
companies operating in the agri-food domain is evident. Recent developments have accelerated the shift to digital and highlighted the relevance of digitalization in agri-food. Technological solutions and digital technologies are catalysts that could enable sustainable and long-lasting CBM. Methodologically, we propose engaged scholarship (Van de Ven, 2007) to be the primary method in activating the collective decision-making processes and value cocreation to alleviate the bottlenecks of agri-food digital transformation.

We confirm Rey-Garcia et al.'s (2021) findings that the conditions imposed on the fields beyond each stakeholder's control influence the evolution of CBM, while stakeholders deal with emerging tensions in the market and the process. This is why CBM is dynamic and nonlinear in uncertain markets. By embracing the ambiguities around IoT applications in agri-food, this research argues for alignment and integration before developing share value proposition strategies. Lopez et al. (2021) show that the traditional valuation mechanisms are based on predetermined assumptions that do not apply to IoT platforms. Io T platforms have special dynamics of their own. For example, the network effect associated with demandrelated strategies in the ecosystems greatly influences value creation and capture strategies in subsystems. The notion of "interconnected business models" has been introduced to conceptualize BMs in the networked ecosystems and address the complexities of new ICT services (Jocevski et al., 2020). We argue that CBM development is necessary for forming ecosystemic, networked business models.

\subsection{Theoretical contributions}

From the theoretical point of view, this research contributes to the literature of digitalization, open innovation and business models in three ways. First, on the nexus of digitalization and value creation, although previous studies showed that digitalization promises self-regulating and inter-connected systemic value creation mechanisms for industries (Liao et al., 2017), our research shows this only can become a reality when all actors align their position toward who they create value for and what is their market position compared to other actors in the ecosystem. Empirical studies connecting digitalization and business model streams of literature mostly assess the effect of digitalization on competitive advantages from a single or focal firm perspective in the supply chain (Caputo et al., 2021) and not from the value chain and ecosystem perspective. Our study is the first step toward realizing how IoT-enabled ecosystem actors can co-create competitive advantage through developing CBMs.

Second, as digitalization becomes "the new normal", our study reveals the need for the agri-food technology providers to gradually switch from traditional product/service-centric business models to more customer-centric business models to thrive on a common ground for systemic value creation. This result contributes to the phenomenon of open innovation in the agri-food industry by unraveling the potential of CBMs in redesigning the agri-food value chains. In addition, most of the research on the phenomenon of OI in the agri-food sector suggest the positive impact of OI implementation on firms' innovation performance and market position (e.g. Bayona-Saez et al., 2017; Miglietta et al., 2017) while our research takes a step back and sheds light on what it takes for agri-food technology providers to engage in a collaborative set-up and innovate their business models. Our study also contributes to the seminal work of Chesbrough (2007) on business model innovation, in which he highlighted that in order to leverage on firm's business model as an adaptive platform, actors should commit and engage actively in experimentation with one or more business model variants. For the case of IoT-enabled agri-food ecosystems, our research showed that interplay and alignment among actors should take effect together (in the form of technology development for farmers, risk-sharing and market position).

Our third contribution lies in the literature of CBMs. Our research showed that implementing a CBM is easier said than done specifically in the context of the agri-food
A smart web of firms, farms and IoT

1869 
$\mathrm{BFJ}$

124,6

industry due to not only its high heterogeneity of actors' absorptive capacity in learning and innovation but also its everchanging market needs and consumer trends. Our empirical analysis contributed to the work of de Man and Luvison (2019) by revealing the antecedents of developing CBMs namely interplay and alignment. However, our contribution to this stream of literature is limited to exploration rather than implementation.

\subsection{Managerial implications}

In this article, we do not directly address the questions of how managers can implement open innovation in the agri-food sector and how the sector can benefit from it. Instead, we direct attention to the density and diversity of the actors involved, and how their complexity informs managers' decision to engage in an open innovation set up. Io T organizations are at the onset of benefiting from open innovation in the agri-food context. However, there is a need for strategy managers to co-develop market demands, align different dimensions of collaboration and make decisions together when there is a high level of uncertainty. However, a single firm cannot dive into such a market or navigate the challenging possibilities. So if a given firm is targeting a new market and there is high uncertainty in this market, then collaboration and developing a CBM could help to share the risk, decrease the uncertainty and enable conditions in which open innovation can thrive.

The insights of this study inspire action and reinforce calls for shared responsibilities and commitments to common goals in developing CBM by all ecosystem actors. When examining the readiness and motivation of IoT-enabled firms operating in the agri-food domain, this research found that the farmers' needs and expectations should be central to the service and technology providers. Based on our earlier discussion points, our study suggests that in engaging with CBM, IoT-enabled agri-food firms should strive to create a new scope of practice, tailor-made and scalable. Managers should pay attention to enabling multidirectional knowledge transfer and to encourage representatives of firms to learn how to work with farmers in offering IoT solutions. It should be noted that the opinions and experiences depicted in this research are based on ongoing collaborations and a high level of familiarity between the research participants. Particular attention should be devoted to establishing and nurturing long-term strategic partnerships among researchers, policymakers and practitioners to enable CBM in the future.

\subsection{Recommendations for future research}

The limitations of this research offer avenues for future research. This research-based qualitative analysis of a set of engagement workshops could only shed light on the phenomenon under investigation. Theory development requires a more inclusive perspective which allows for generalizability. Multiple levels of analysis should be integrated into a longitudinal study to present the reader with a comprehensive overview and a theoretical framework. In addition, future research should include direct and indirect agri-food ecosystem stakeholders, late technology adaptors, farmers cooperatives and consumers to understand the IoT-enabled ecosystem dynamics better.

\section{References}

Accorsi, R., Bortolini, M., Baruffaldi, G., Pilati, F. and Ferrari, E. (2017), "Internet-of-things paradigm in food supply chains control and management", Procedia Manufacturing, Vol. 11, pp. 889-895.

Adner, R. (2017), "Ecosystem as structure: an actionable construct for strategy", Journal of Management, Vol. 43 No. 1, pp. 39-58.

Adner, R. and Kapoor, R. (2010), "Value creation in innovation ecosystems: how the structure of technological interdependence affects firm performance in new technology generations", Strategic Management Journal, Vol. 31 No. 3, pp. 306-333. 
Alassaf, D., Dabić, M., Shifrer, D. and Daim, T. (2020), "The impact of open-border organization culture and employees' knowledge, attitudes, and rewards with regards to open innovation: an empirical study", Journal of Knowledge Management, Vol. 24 No. 9, pp. 2273-2297.

Amit, R. and Zott, C. (2012), "Creating value through business model innovation", MIT Sloan Management Review, Vol. 53 No. 3, pp. 41-49.

Annosi, M.C., Marzi, G., Ciampi, F. and Rialti, R. (2020), "An ambidextrous approach to practice-based innovation for social product development: lessons from a Dutch company", IEEE Transactions on Engineering Management, Vol. 69 No. 2, pp. 376-387.

Bayona-Saez, C., Cruz-Cázares, C., García-Marco, T. and García, M.S. (2017), "Open innovation in the food and beverage industry”, Management Decision, Vol. 55 No. 3, pp. 526-546.

Bitzer, V. and Bijman, J. (2015), "From innovation to co-innovation? An exploration of African agrifood chains", British Food Journal, Vol. 117 No. 8, pp. 2182-2199.

Blee, K.M. and Taylor, V. (2002), "Semi-structured interviewing in social movement research", Methods of Social Movement Research, Vol. 16, pp. 92-117.

Bossink, B.A. (2002), "The development of co-innovation strategies: stages and interaction patterns in interfirm innovation”, R\&D Management, Vol. 32 No. 4, pp. 311-320.

Bresciani, S. (2017), "Open, networked and dynamic innovation in the food and beverage industry", British Food Journal, Vol. 119 No. 11, pp. 2290-2293.

Bresciani, S., Ferraris, A. and Del Giudice, M. (2018), "The management of organizational ambidexterity through alliances in a new context of analysis: Internet of Things (IoT) smart city projects", Technological Forecasting and Social Change, Vol. 136, pp. 331-338.

Breuer, H., Fichter, K., Lüdeke-Freund, F. and Tiemann, I. (2018), "Sustainability-oriented business model development: principles, criteria and tools", International Journal of Entrepreneurial Venturing, Vol. 10 No. 2, pp. 256-286.

Burkhart, T., Krumeich, J., Werth, D. and Loos, P. (2011), "Analyzing the business model concept-a comprehensive classification of literature", 32nd International Conference on Information Systems.

Cantele, S. and Cassia, F. (2020), "Sustainability implementation in restaurants: a comprehensive model of drivers, barriers, and competitiveness-mediated effects on firm performance", International Journal of Hospitality Management, Vol. 87, p. 102510.

Caputo, A., Pizzi, S., Pellegrini, M.M. and Dabić, M. (2021), "Digitalization and business models: where are we going? A science map of the field", Journal of Business Research, Vol. 123, pp. 489-501.

Caridà, A., Colurcio, M. and Melia, M. (2015), "Designing a collaborative business model for SMEs", Sinergie Italian Journal of Management, Vol. 33 Nos Sep-Dec, pp. 233-253.

Chesbrough, H. (2007), "Business model innovation: it's not just about technology anymore", Strategy \& Leadership, Vol. 35 No. 6, pp. 12-17.

Chesbrough, H. and Bogers, M. (2014), "Explicating open innovation: clarifying an emerging paradigm for understanding innovation", in Chesbrough, H., Vanhaverbeke, W. and West, J. (Eds), New Frontiers in Open Innovation, Oxford University Press, Oxford, Forthcoming, pp. 3-28, available at SSRN: https://ssrn.com/abstract $=2427233$.

Cosenz, F. and Noto, G. (2018), "A dynamic business modelling approach to design and experiment new business venture strategies”, Long Range Planning, Vol. 51 No. 1, pp. 127-140.

Dattée, B., Alexy, O. and Autio, E. (2018), "Maneuvering in poor visibility: how firms play the ecosystem game when uncertainty is high", Academy of Management Journal, Vol. 61 No. 2, pp. 466-498.

de Man, A.P. and Luvison, D. (2019), "Collaborative business models: aligning and operationalizing alliances”, Business Horizons, Vol. 62 No. 4, pp. 473-482.

Del Giudice, M. (2016), "Discovering the Internet of Things (IoT) within the business process management: a literature review on technological revitalization", Business Process Management Journal, Vol. 22 No. 2, pp. 263-270.
A smart web of firms, farms and IoT 
$\mathrm{BFJ}$

124,6

1872

Demil, B. and Lecocq, X. (2010), "Business model evolution: in search of dynamic consistency", Long Range Planning, Vol. 43 Nos 2-3, pp. 227-246.

Dussauge, P., Garrette, B. and Mitchell, W. (2000), "Learning from competing partners: outcomes and durations of scale and link alliances in Europe, North America and Asia", Strategic Management Journal, Vol. 21 No. 2, pp. 99-126.

FAO (2020), Adjusting Business Models to Sustain Agri-Food Enterprises during COVID-19, Rome. doi: 10.4060/ca8996en.

Geissdoerfer, M., Bocken, N.M. and Hultink, E.J. (2016), "Design thinking to enhance the sustainable business modelling process-A workshop based on a value mapping process", Journal of Cleaner Production, Vol. 135, pp. 1218-1232.

Ghezzi, A., Cavallo, A., Sanasi, S. and Rangone, A. (2021), "Opening up to startup collaborations: open business models and value co-creation in SMEs", Competitiveness Review: An International Business Journal, Vol. 32 No. 7, pp. 40-61.

Giesen, E., Riddleberger, E., Christner, R. and Bell, R. (2010), "When and how to innovate your business model", Strategy \& Leadership, Vol. 38 No. 4, pp. 17-26.

Grant, R.M. and Baden-Fuller, C. (2004), "A knowledge accessing theory of strategic alliances”, Journal of Management Studies, Vol. 41 No. 1, pp. 61-84.

Jacobides, M.G., Knudsen, T. and Augier, M. (2006), "Benefiting from innovation: value creation, value appropriation and the role of industry architectures", Research Policy, Vol. 35 No. 8, pp. 1200-1221.

Jagtap, S., Bhatt, C., Thik, J. and Rahimifard, S. (2019), "Monitoring potato waste in food manufacturing using image processing and internet of things approach", Sustainability, Vol. 11 No. 11, p. 3173.

Jocevski, M., Arvidsson, N. and Ghezzi, A. (2020), "Interconnected business models: present debates and future agenda", Journal of Business \& Industrial Marketing, Vol. 35 No. 6, pp. 1051-1067.

Joyce, A. and Paquin, R.L. (2016), "The triple layered business model canvas: a tool to design more sustainable business models", Journal of Cleaner Production, Vol. 135, pp. 1474-1486.

Kafetzopoulos, D., Vouzas, F. and Skalkos, D. (2020), "Developing and validating an innovation drivers' measurement instrument in the agri-food sector", British Food Journal, Vol. 122 No. 4, pp. 1199-1214.

Kranz, J.J., Hanelt, A. and Kolbe, L.M. (2016), "Understanding the influence of absorptive capacity and ambidexterity on the process of business model change-the case of on-premise and cloudcomputing software", Information Systems Journal, Vol. 26 No. 5, pp. 477-517.

Laudien, S.M. and Daxböck, B. (2016), "Path dependence as a barrier to business model change in manufacturing firms: insights from a multiple-case study", Journal of Business Economics, Vol. 86 No. 6, pp. 611-645.

Lepak, D.P., Smith, K.G. and Taylor, M.S. (2007), "Value creation and value capture: a multilevel perspective”, Academy of Management Review, Vol. 32 No. 1, pp. 180-194.

Leung, F.H. and Savithiri, R. (2009), "Spotlight on focus groups", Canadian Family Physician, Vol. 55 No. 2, pp. 218-219.

Lezoche, M., Hernandez, J.E., Díaz, M.D.M.E.A., Panetto, H. and Kacprzyk, J. (2020), “Agri-food 4.0: a survey of the supply chains and technologies for the future agriculture", Computers in Industry, Vol. 117, p. 103187.

Liao, S.H., Hu, D.C. and Ding, L.W. (2017), "Assessing the influence of supply chain collaboration value innovation, supply chain capability and competitive advantage in Taiwan's networking communication industry”, International Journal of Production Economics, Vol. 191, pp. 143-153.

Liu, Z. and Stephens, V. (2019), "Exploring innovation ecosystem from the perspective of sustainability: towards a conceptual framework", Journal of Open Innovation: Technology, Market, and Complexity, Vol. 5 No. 3, p. 48. 
Lopez, C.A., Castillo, L.F. and Corchado, J.M. (2021), "Discovering the value creation system in IoT ecosystems", Sensors, Vol. 21 No. 2, p. 328.

Mäkimattila, M., Melkas, H. and Uotila, T. (2013), "Dynamics of openness in innovation processes-a case study in the Finnish food industry", Knowledge and Process Management, Vol. 20 No. 4, pp. 243-255.

Metallo, C., Agrifoglio, R., Schiavone, F. and Mueller, J. (2018), "Understanding business model in the Internet of Things industry", Technological Forecasting and Social Change, Vol. 136, pp. 298-306.

Miglietta, N., Battisti, E. and Campanella, F. (2017), "Value maximization and open innovation in food and beverage industry: evidence from US market”, British Food Journal, Vol. 119 No. 11, pp. 2477-2492.

Mondino, P. and González-Andújar, J.L. (2019), "Evaluation of a decision support system for crop protection in apple orchards", Computers in Industry, Vol. 107, pp. 99-103.

Müller, J.M., Buliga, O. and Voigt, K.I. (2018), "Fortune favors the prepared: how SMEs approach business model innovations in Industry 4.0", Technological Forecasting and Social Change, Vol. 132, pp. 2-17.

Obradović, T., Vlačić, B. and Dabić, M. (2021), "Open innovation in the manufacturing industry: a review and research agenda", Technovation, Vol. 102 No. 3, pp. 1-16.

Oskam, I., Bossink, B. and de Man, A.P. (2021), "Valuing value in innovation ecosystems: how crosssector actors overcome tensions in collaborative sustainable business model development", Business \& Society, Vol. 60 No. 5, pp. 1059-1091.

Porter (1985), “Technology and competitive advantage”, Journal of Business Strategy, Vol. 5 No. 3, pp. 60-78, doi: 10.1108/eb039075.

Rashid, A., Asif, F.M., Krajnik, P. and Nicolescu, C.M. (2013), "Resource conservative manufacturing: an essential change in business and technology paradigm for sustainable manufacturing", Journal of Cleaner Production, Vol. 57, pp. 166-177.

Renda, A. and Laurer, M. (2020), Io T 4 SDGs-What Can the Digital Transformation and IoT Achieve for Agenda 2030? (No. 26658), Centre for European Policy Studies, Brussels.

Rey-Garcia, M., Mato-Santiso, V. and Felgueiras, A. (2021), "Transitioning collaborative cross-sector business models for sustainability innovation: multilevel tension management as a dynamic capability", Business \& Society, Vol. 60 No. 5, pp. 1132-1173.

Ritala, P., Agouridas, V., Assimakopoulos, D. and Gies, O. (2013), "Value creation and capture mechanisms in innovation ecosystems: a comparative case study", International Journal of Technology Management, Vol. 63 Nos 3-4, pp. 244-267.

Saebi, T. and Foss, N.J. (2015), "Business models for open innovation: matching heterogeneous open innovation strategies with business model dimensions", European Management Journal, Vol. 33 No. 3, pp. 201-213.

Schaffer, N., Pfaff, M. and Krcmar, H. (2019), "Dynamic business models: a comprehensive classification of literature", Thirteenth Mediterranean Conference on Information Systems, (MCIS 2019).

Schneider, S. and Spieth, P. (2013), "Business model innovation: towards an integrated future research agenda”, International Journal of Innovation Management, Vol. 17 No. 01, p. 1340001.

Schoen, A.P. (2017), "Openness and collaboration in the food sector: mapping the field", British Food Journal, Vol. 119 No. 11, pp. 2493-2506.

Schuh, G., Anderl, R., Gausemeier, J., ten Hompel, M. and Wahlster, W. (2017), "Industrie 4.0 maturity index", Managing the Digital Transformation of Companies, Munich: Herbert Utz.

Schwarz, G. and Stensaker, I. (2016), "Showcasing phenomenon-driven research on organizational change”, Journal of Change Management, Vol. 16 No. 4, pp. 245-264, doi: 10.1080/14697017.2016. 1230931.
A smart web of firms, farms and IoT 
$\mathrm{BFJ}$

124,6

1874

Trimi, S. and Berbegal-Mirabent, J. (2012), "Business model innovation in entrepreneurship", International Entrepreneurship and Management Journal, Vol. 8 No. 4, pp. 449-465.

Van de Ven, A.H. (2007), Engaged Scholarship: A Guide for Organizational and Social Research, Oxford University Press on Demand, Oxford.

van Hilten, M., Adema, H., Nuhoff-Isakhanyan, G. and Otte, H. (2020), Validation of User Acceptability in IoF2020 Use Cases WP 4. IoF2020.

van Putten, B.J. and Schief, M. (2013), "The relation between dynamic business models and business cases", Supporting Reuse in Business Case Development, Springer Gabler, Wiesbaden, pp. 118-133.

Von Krogh, G., Rossi-Lamastra, C. and Haefliger, S. (2012), "Phenomenon-based research in management and organisation science: when is it rigorous and does it matter?", Long Range Planning, Vol. 45 No. 4, pp. 277-298.

Wei, Z., Yang, D., Sun, B. and Gu, M. (2014), "The fit between technological innovation and business model design for firm growth: evidence from China”, R\&D Management, Vol. 44 No. 3, pp. 288-305.

Wei, Z., Song, X. and Wang, D. (2017), "Manufacturing flexibility, business model design, and firm performance", International Journal of Production Economics, Vol. 193, pp. 87-97.

Wirtz, B.W., Pistoia, A., Ullrich, S. and Göttel, V. (2016), "Business models: origin, development and future research perspectives”, Long Range Planning, Vol. 49 No. 1, pp. 36-54.

Ying, F. and Fengquan, L. (2013), "Application of internet of things to the monitoring system for food quality safety", 2013 Fourth International Conference on Digital Manufacturing \& Automation, IEEE, pp. 296-298.

Zott, C. and Amit, R. (2010), "Business model design: an activity system perspective", Long Range Planning, Vol. 43 Nos 2-3, pp. 216-226.

\section{Further reading}

Del Giudice, M. and Della Peruta, M.R. (2016), "The impact of IT-based knowledge management systems on internal venturing and innovation: a structural equation modeling approach to corporate performance", Journal of Knowledge Management.

Zott, C., Amit, R. and Massa, L. (2011), "The business model: recent developments and future research", Journal of Management, Vol. 37 No. 4, pp. 1019-1042.

\section{Corresponding author}

Maral Mahdad can be contacted at: maral.mahdad@wur.nl

For instructions on how to order reprints of this article, please visit our website:

www.emeraldgrouppublishing.com/licensing/reprints.htm

Or contact us for further details: permissions@emeraldinsight.com 